\title{
Original
}

\section{Ozone Water Bactericidal and Cleaning Effects on Oral Diseases-related Planktonic and Bacterial Biofilms}

\author{
Masahiro Murakami $^{1,2)}$, Keiji Nagano ${ }^{3)}$, Kouichi Hamaoka ${ }^{4)}$, Daisuke Kato ${ }^{1)}$, Tatsushi Kawai ${ }^{5)}$, Hiroshi Murakami ${ }^{1)}$ and Yoshiaki Hasegawa ${ }^{2)}$ \\ ${ }^{1)}$ Department of Gerodontology and Home Care Dentistry, Aichi Gakuin University, Nagoya, Japan \\ ${ }^{2}$ Department of Microbiology, School of Dentistry, Aichi Gakuin University, Nagoya, Japan \\ ${ }^{3)}$ Division of Microbiology, Department of Oral Biology, School of Dentistry, Health Sciences University of Hokkaido, Hokkaido, Japan \\ ${ }^{4}$ Maxell, Ltd., Kyoto, Japan \\ ${ }^{5)}$ Department of Dental Materials Science, School of Dentistry, Aichi Gakuin University, Nagoya, Japan \\ (Accepted for publication, October 1, 2020)
}

\begin{abstract}
Ozone water has long been known as a bactericidal disinfectant. However, the bactericidal effect of ozone water on bacteria associated with oral diseases has not been thoroughly examined. Further, although oral bacteria reside in biofilms, few studies have explored the effects of ozone water on biofilms. In this study, we aimed to investigate the bactericidal effect of ozone water on bacteria and bacterial biofilms associated with oral diseases. We examined the bactericidal and cleaning effects of ozone water on pathogenic bacteria associated with oral diseases (Staphylococcus aureus, Pseudomonas aeruginosa, Streptococcus mutans, and Porphyromonas gingivalis) under planktonic and biofilm growth conditions. When planktonic bacteria were exposed to 5-ppm ozone water, a remarkable antibacterial activity was observed against all of the tested bacterial species. Contrarily, biofilms showed high resistance to ozone water; the bacterial load only slightly decreased even after repeated exposure to ozone water. However, when ozone water was continuously applied at a low flow rate to the biofilms on polystyrene disks, the number of bacteria on the disks was significantly decreased. Our results have shown that the continuous application of ozone water can eliminate oral disease-related bacteria even in biofilms.
\end{abstract}

Key words: Ozone water, Bactericidal, Planktonic, Biofilm, Oral

\section{Introduction}

Ozone water, produced by dissolving ozone gas in water, presents a robust microbicidal activity; the ozone molecules in water can kill microorganisms by oxidizing the surface molecules and nucleic acids ${ }^{1)}$. It is currently used for disinfection in the food industry ${ }^{2,3)}$ and in medicine and dentistry since the $1800 \mathrm{~s}^{4)}$ and $1930^{5}$, respectively. More recently, additional beneficial effects of ozone water, such as anti-inflammation ${ }^{6}$ and wound repair activities ${ }^{7}$ have been reported. However, the use of ozone water in dentistry is not always common due to a lack of evidence regarding its effects.

Oral diseases such as dental caries and periodontitis are caused by bacteria that colonize oral tissues through biofilm formation ${ }^{8}$. Biofilm bacteria firmly adhere to the surface of solid materials and mucus membranes in organisms through a net of extracellular matrices consisting of peptides and sugars ${ }^{9,10)}$. Medical treatments often face difficulties in biofilm elimination because biofilm bacteria, in addition to presenting robust colonization of host tissues, present significantly increased resistance against antibiotics and disinfectants ${ }^{10)}$. Although ozone water is used for dental therapy as described above, only a few studies have reported the effects of ozone water on biofilm bacteria ${ }^{11-13)}$.

In this study, we examined the bactericidal and cleaning effects of ozone water using four bacterial species (Streptococcus mutans, Por-

Correspondence to: Dr. Keiji Nagano, Division of Microbiology, Department of Oral Biology, School of Dentistry, Health Sciences University of Hokkaido, 1757 Kanazawa, Tobetsu-cho, Ishikari-gun, Hokkaido 061-0293, Japan; Tel: +81-133-23-2413; E-mail: knagano@hoku-iryo-u.ac.jp phyromonas gingivalis, Staphylococcus aureus, and Pseudomonas aeruginosa) under plankton and biofilm growth conditions. Cariogenic bacterium $S$. mutans, a gram-positive facultatively anaerobic coccus, forms a sticky biofilm on teeth primarily by producing water-insoluble glucan from sucrose ${ }^{14,15)}$. P. gingivalis, a gram-negative anaerobic rod, is closely associated with periodontal diseases ${ }^{16}$. It colonizes the gingival crevice along with a multi-species biofilm, leading the microbial composition to dysbiosis and resulting in chronic inflammatory disease $^{17,18)}$. S. aureus, a gram-positive facultatively anaerobic coccus, and $P$. aeruginosa, a gram-negative aerobic rod, are known as opportunistic pathogens. Their multidrug-resistant strains, such as methicillin-resistant $S$. aureus (MRSA) and multidrug-resistant $P$. aeruginosa (MDRP), currently cause a critical medical problem worldwide due to the absence of effective drugs against them ${ }^{19)}$. Although $S$. aureus and P. aeruginosa are not always detected in the oral cavity, they cause refractory inflammation in oral mucosa and root canal because they can survive after disinfection and antibiotic treatment in dental therapy procedures ${ }^{20,21)}$.

In this work, we demonstrate that the direct application of ozone water effectively destroyed planktonic bacteria, whereas it was not able to remove biofilms completely. On the other hand, a continuous flow of ozone water could effectively eliminate biofilms.

\section{Materials and Methods \\ Bacterial strains and culture conditions}

The bacterial strains and culture conditions that were used in this work are summarized in Table 1. We used the sucrose-containing medi- 
J.Hard Tissue Biology Vol. 30(1): 27-32, 2021

Table 1. Bacterial strains and culture conditions

\begin{tabular}{|c|c|c|c|c|c|c|}
\hline \multirow{2}{*}{ Bacteria } & \multirow{2}{*}{ Strain } & \multirow{2}{*}{$\begin{array}{l}\text { Culture } \\
\text { Condition }^{\mathrm{a}}\end{array}$} & \multicolumn{2}{|l|}{ Medium $^{\text {b }}$} & \multicolumn{2}{|c|}{ Initial concentration $^{c}$} \\
\hline & & & Plankton & Biofilm & OD600 & $(\mathrm{CFU} / \mathrm{mL})$ \\
\hline S. aureus & FDA 209P & Aerobic & $\mathrm{BHI}$ & BHI with $5 \%$ sucrose & 0.01 & $\left(5.0 \times 10^{7}\right)$ \\
\hline P. aeruginosa & PAO1 & Aerobic & BHI & BHI & 0.01 & $\left(8.0 \times 10^{6}\right)$ \\
\hline S. mutans & $\mathrm{XC}$ & $5 \% \mathrm{CO}_{2}$ & BHI & BHI with $5 \%$ sucrose & 0.01 & $\left(1.0 \times 10^{6}\right)$ \\
\hline \multirow[t]{2}{*}{ P. gingivalis } & ATCC 33277 & Anaerobic & mGAM & mGAM & 0.1 & $\left(1.0 \times 10^{8}\right)$ \\
\hline & HG405 & Anaerobic & mGAM & mGAM & 0.1 & $\left(1.0 \times 10^{8}\right)$ \\
\hline
\end{tabular}

${ }^{a}$ Bacteria were cultivated at $37^{\circ} \mathrm{C}$ under aeration (aerobic), air supplemented with $5 \% \mathrm{CO}_{2}\left(5 \% \mathrm{CO}_{2}\right.$ ), or $80 \% \mathrm{~N}_{2}, 10 \% \mathrm{CO}_{2}$, and $10 \%$ $\mathrm{H}_{2}$ (anaerobic) conditions.

${ }^{b}$ BHI, brain-heart infusion broth; mGAM, GAM broth, Modified (Nissui Pharmaceutical Co., Ltd., Tokyo, Japan). For the biofilm assays of $S$. aureus and $S$. mutans, $5 \%$ sucrose was added to the medium.

${ }^{c}$ The initial bacterial concentrations were chosen according to a previous study in order to obtain a reproducible growth pattern ${ }^{24)}$. Bacterial concentrations (CFU/ $\mathrm{ml}$ ) are estimated from OD600 values using a standard curve (data not shown).

um to induce biofilm formation by $S$. aureus FDA 209P and S. mutans XC. It is well known that $S$. mutans forms a strong biofilm by secreting water-insoluble glucan when grown in a sucrose-containing medium ${ }^{15}$, and we found that this also happened with $S$. aureus FDA 209P (data not shown). We used two strains of $P$. gingivalis, ATCC 33277 and HG405, as a standard type strain and one capable of forming biofilm ${ }^{22)}$, respectively. All strains were maintained on agar plates, and cultures in liquid media grown up to the beginning of the stationary phase were used in each experiment.

\section{Ozone water preparation}

Ozone water was prepared from tap water by a dielectric-barrier discharge ozone generator (E-25-S, Suisei Factory Corporation, Amagasaki, Japan) at a concentration of 5 ppm (approximately $0.1 \mathrm{mM}$ ). Ozone water was used immediately (within $10 \mathrm{~s}$ ) after preparation because ozone decays rapidly in water ${ }^{23)}$. Ozone concentration was continuously monitored with an ozone meter. Sterile tap water and sodium hypochlorite $(\mathrm{NaOCl})$ were used as negative and positive controls, respectively.

\section{Effect of ozone water on planktonic bacteria}

Bacterial cultures were diluted to an optical density of 0.01 or 0.1 at a 600-nm wavelength (OD600) with phosphate-buffered saline (PBS) pH 7.4 (Table 1). When preparing anaerobic bacterium (P. gingivalis), PBS was supplemented with a reducing agent $(1 \mathrm{mM}$ dithiothreitol, DTT). Aliquots of $0.1 \mathrm{ml}$ of the bacterial suspensions were applied to one well out of a 96-well filter plate $(0.22-\mu \mathrm{m}$ filter, Merck KGaA, Darmstadt, Germany), and the liquid portion was removed through the bottom filter of the plate by aspirating. To wash the bacterial cells and wells, $0.1 \mathrm{ml}$ of PBS (or PBS with $1 \mathrm{mM}$ DTT for $P$. gingivalis) was added to the plate and removed by aspiration. Then, $0.1 \mathrm{ml}$ of ozone water (5 ppm) was added to each well, and the plate was incubated for $30 \mathrm{~s}$ at room temperature. When repeating the ozone treatment two or three times, the liquid was removed by aspiration, and fresh ozone water was added to the well. After the treatment, $0.1 \mathrm{ml}$ of culture medium was added to the final mixture to inactivate the ozone in water. After removing the remaining liquid, bacteria were suspended in $0.1 \mathrm{ml}$ of PBS (or PBS with $1 \mathrm{mM}$ DTT). Serial dilutions of each bacterial suspension were spread on agar plates, and the colony-forming units (CFUs) were enumerated after cultivation ${ }^{24)}$.

\section{Effect of ozone water on biofilm bacteria}

Bacterial cultures were prepared in fresh liquid media (Table 1), according to a previous study ${ }^{24)}$. Aliquots of $0.1 \mathrm{ml}$ were transferred to a 96-well polystyrene plate, which was incubated overnight to induce biofilm formation. The culture solution was then decanted, and the plate was tapped on a sterile paper towel to remove the liquid portion completely. Biofilms were washed once with $0.1 \mathrm{ml}$ of PBS or PBS with 1 mM DTT (for $P$. gingivalis), then $0.1 \mathrm{ml}$ of ozone water (5 ppm) was added to each well and incubated for $30 \mathrm{~s}$ at room temperature. When treatment was repeated two or three times, the previous liquid portion was completely removed before adding the next ozone water aliquot. After treatment, $0.1 \mathrm{ml}$ of culture medium was added to each well to inactivate the ozone in water. After removing the liquid by decanting and tapping, $0.1 \mathrm{ml}$ of PBS (or PBS with $1 \mathrm{mM}$ DTT) was added, and the biofilm bacteria were collected by swabbing. The swab heads were soaked in $1 \mathrm{ml}$ of PBS (or PBS with $1 \mathrm{mM}$ DTT) and vigorously mixed to release the bacteria into a suspension. Serial dilutions of the bacterial suspensions were spread on agar plates, and the CFUs were enumerated after incubation.

\section{Effect of flowing ozone water on biofilm bacteria}

Polystyrene disks (5 $\mathrm{mm}$ in diameter, $1 \mathrm{~mm}$ in thickness) were prepared and sterilized with ethylene oxide gas. The disks were immersed in brain-heart infusion (BHI; Becton, Dickinson and Company, Franklin, USA) broth containing 5\% sucrose. S. aureus FDA 209P was inoculated into the broth and incubated overnight to induce biofilm formation. The disks were transferred to a glass 14-cm, 250-ml Petri dish, and then continuous flows of sterile water, 5 ppm ozone water, 5 and 200 ppm $\mathrm{NaOCl}$ were applied at $150-350 \mathrm{ml} / \mathrm{min}$ for $12 \mathrm{~min}$ at room temperature. The flow rates were low and did not exert too much pressure on the disk. Finally, disks were washed in sterile water to remove the disinfectants and were placed in a $15-\mathrm{ml}$ test tube containing $1 \mathrm{ml}$ PBS. Bacteria on the disks were collected by vortexing for $10 \mathrm{~s}$ and then sonicated in an ultrasonic bath (Bransonic 220, YAMATO, Tokyo, Japan) for 5 min. The bacterial numbers were counted as described above.

\section{Statistical analysis}

Data were expressed as means \pm standard deviations (SDs). Oneway analysis of variance (ANOVA) and Tukey's multiple comparison tests were performed using IBM SPSS statistics version 26.0, and results were considered statistically significant when $P$ values were $<0.01$.

\section{Results}

\section{Effect of ozone water on planktonic bacteria}

We firstly examined the bactericidal effect of ozone water on planktonic bacteria (Fig. 1). When the control treatment with water was per- 
(A) S. aureus

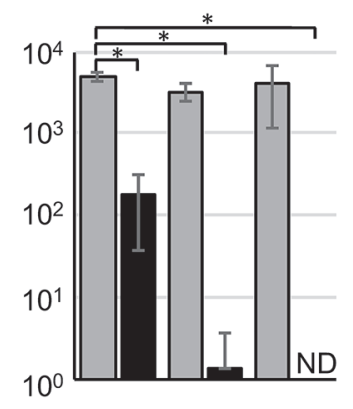

(B) $P$. aeruginosa

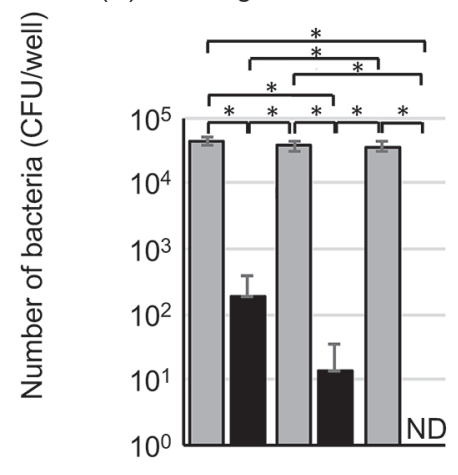

(C) S. mutans

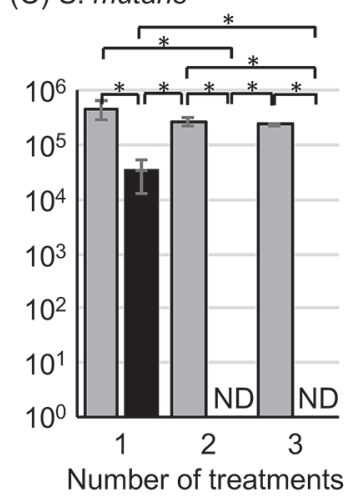

Figure 1. Bactericidal effect of ozone water on planktonic bacteria. Planktonic bacteria (bacterial suspensions) of S. aureus (A), P. aeruginosa (B), $S$. mutans (C), P. gingivalis ATCC 33277 (D), and P. gingivalis HG405 (E) were treated once, twice, or three times with water (black bars) and 5-ppm ozone water (gray bars) for $30 \mathrm{~s}$. After treatment, surviving bacteria were measured in terms of CFU counts ( $n=3$ in A-C, $n=4$ in D and E). Data show means \pm SDs. ND indicates that bacteria were not detected (below 2 $\mathrm{CFU} /$ well). ND indicates that bacteria were not detected (below $2 \mathrm{CFU} /$ well). * denotes statistically significant difference at $P<0.01$.

formed, one, two, or three times, the bacterial counts (CFU/well) of $S$. aureus, $P$. aeruginosa, and $S$. mutans were unchanged, whereas ozone water treatments significantly decreased their counts even with a single treatment. Bacterial counts decreased further after the second treatment and fell below the detection limit after the third treatment. CFUs of the two strains of $P$. gingivalis declined gradually even with the control wa-
(A) S. aureus

(D) P. gingivalis ATCC 33277
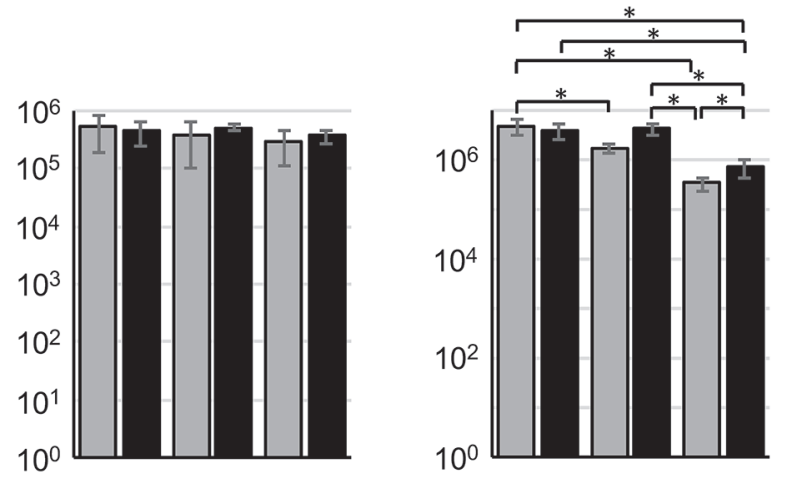

(B) $P$. aeruginosa

(E) $P$. gingivalis HG405
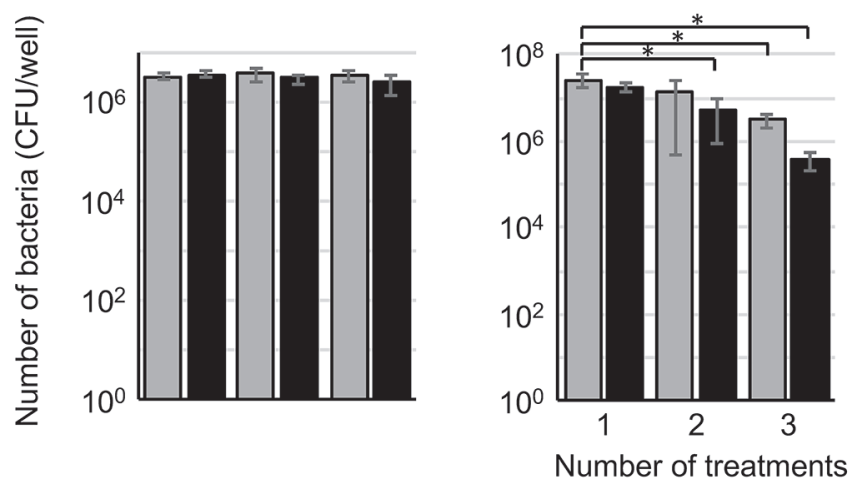

(C) S. mutans

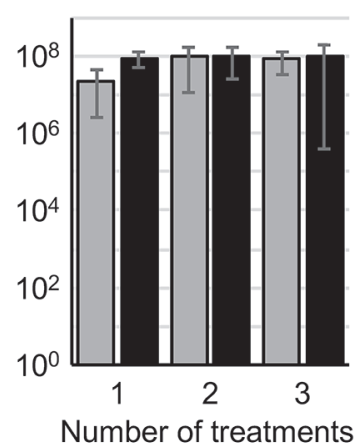

Figure 2. Cleaning effect of ozone water on biofilm bacteria. Biofilms of $S$. aureus (A), P. aeruginosa (B), S. mutans (C), P. gingivalis ATCC 33277 (D), and $P$. gingivalis HG405 (E) were treated once, twice, or three times with water (black bars) and 5-ppm ozone water (gray bars) for $30 \mathrm{~s}$. After treatment, the remaining bacteria were measured in terms of CFU counts (n $=3$ in $\mathrm{A}-\mathrm{C}, \mathrm{n}=4$ in $\mathrm{D}$ and E). Data show means \pm SDs. ND indicates that bacteria were not detected (below $2 \mathrm{CFU} /$ well). * denotes statistically significant difference at $P<0.01$.

ter treatment, while the ozone water treatment caused a statistically significant decrease in both strains; however, the treatment's bactericidal effects were deemed weak as the difference from the control with water was not significant.

\section{Effect of ozone water on biofilm bacteria}

Next, we examined the cleaning effects of ozone water on biofilm bacteria (Fig. 2). Because in this experiment, the plate wells were 
J.Hard Tissue Biology Vol. 30(1): 27-32, 2021

\section{S. aureus}

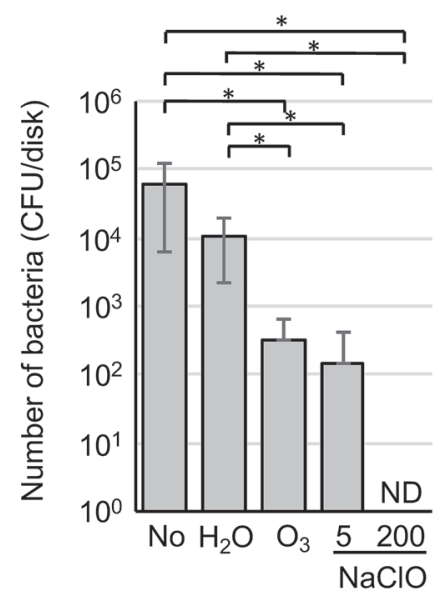

Figure 3. Cleaning effect of flowing ozone water on biofilm bacteria. S. aureus biofilm was formed on a polystyrene disk. The disks were then soaked in moderately flowing water $\left(\mathrm{H}_{2} \mathrm{O}\right), 5$-ppm ozone water $\left(\mathrm{O}_{3}\right)$, and 5-ppm (5), and 200-ppm (200) sodium hypochlorite ( $\mathrm{NaClO})$. After treatment, the remaining bacteria were measured in terms of CFU counts $(n=7)$. "No" indicates the non-treated group. Data show means \pm SDs. ND indicates that bacteria were not detected (below $10 \mathrm{CFU} /$ disk). ND indicates that bacteria were not detected (below $2 \mathrm{CFU} /$ well). $*$ denotes statistically significant difference at $P<0.01$.

washed between treatments, bacterial numbers were also affected by the washing effect of water and ozone water treatments. There were no signs of a reduction in viable counts of $S$. aureus, $P$. aeruginosa, and $S$. mutans biofilms even after three treatments with ozone water, as well as with water. $P$. gingivalis strains showed a slight decrease in CFUs after water and ozone water treatments.

\section{Effect of flowing ozone water on biofilm bacteria}

Finally, we examined the cleaning effect of flowing ozone water on biofilm bacteria using a polystyrene disk (Fig. 3). In this experiment, we used $S$. aureus because it forms a tight biofilm and is resistant to oxygen exposure and to the sonic treatment used to collect bacteria from the disk. A moderate water flow displayed a slight decrease in the number of bacteria collected from the disk in comparison to the non-treatment group. Ozone water caused a significant decrease in bacterial numbers in comparison to water, being comparable to treatment with 5-ppm $\mathrm{NaOCl}$. Treatment with 200 -ppm $\mathrm{NaOCl}$ completely washed out the bacteria from the disk.

\section{Discussion}

We used a 96 -well filter plate $(0.22-\mu \mathrm{m}$ filter $)$ to examine the bactericidal effect of ozone water on planktonic bacteria. The plate retained bacterial cells in its wells without any cell losses during the washing process. In the biofilm experiment, we examined the cleaning effects of ozone water, including bactericidal and washing (detaching) effects, using a static treatment where ozone water was poured in the wells and discarded between treatments. Considering the results obtained in this study, we believe that ozone water treatment, as proposed in our work, should be discussed for dental therapy. In the flowing water experiment, we placed polystyrene disks with bacterial biofilms in a large dish (250$\mathrm{ml}$ volume) and applied water, hypochlorite, or ozone water at a rate that was almost equal to the dish volume per minute. The disks were very light and barely sunk, but did not move while the flowing water was applied, suggesting that the physical stress from the flowing water was negligible.

In planktonic growth conditions, $S$. aureus, $P$. aeruginosa, and $S$. mutans were remarkably killed by treatment with ozone water even in a small amount $(0.1 \mathrm{ml})$ for a short period $(30 \mathrm{~s})$ (Fig. 1). These results confirm the strong bactericidal effect of ozone water on gram-positive and gram-negative bacteria. Regarding the two strains of $P$. gingivalis, bacterial count reductions were relatively small compared to the other three species but were still statistically significant compared to the controls. We prepared $P$. gingivalis strains using a buffer supplemented with a reducing agent DTT to counteract the atmospheric oxygen because anaerobic bacteria are extraordinarily sensitive to oxygen. Indeed, viable counts of $P$. gingivalis were reduced by treatment with normal water, indicating that oxygen exposures during the experimental procedure could have caused a decrease in $P$. gingivalis viability. However, the reducing agent also counteracts ozone. Although the buffer containing DTT was removed before the addition of ozone water, a trace amount of DTT might be able to counteract the effects of ozone. There is, therefore, a practical difficulty in examining the effects of ozone on anaerobic bacteria. Nevertheless, we would like to note that ozone water showed a statistically significant reduction in the numbers of viable cells of anaerobes in our experimental conditions.

Biofilms are formed by a net of extracellular matrices composed of organic compounds such as proteins and carbohydrates produced by the component bacteria ${ }^{9,10)}$. The ozone molecules could not degrade the extracellular matrices when used in small amounts and short treatments, therefore showing no reduction in the number of biofilm-forming bacteria in these conditions (Fig. 2). P. gingivalis biofilms showed a slight sensitivity to ozone water, but also normal water, indicating again that this bacterium was affected by exposure to oxygen during the experiment. Because ozone water effectively eliminated the planktonic bacteria tested in this study but not biofilms, we concluded that the ozone molecules in water could not reach the bacterial cells due to the extracellular matrices of biofilms. Our results also showed that short-term exposure to a small amount of ozone could not degrade the extracellular matrices.

Huth et al. examined the bactericidal effect of ozone water on biofilms and planktonic forms of oral bacteria, including $P$. gingivalis, showing that ozone water exhibited a bactericidal effect on biofilms, although in a weaker manner than on planktonic bacteria ${ }^{13)}$. In this study, biofilms were treated with ozone water for a minute with agitation, suggesting that oxygen exposure and agitation increased the effects of ozone water. Hems et al. showed a bactericidal effect of ozone water on the biofilm of Enterococcus faecalis ${ }^{12)}$, which can cause oral infections, as seen by $S$. aureus and $P$. aeruginosa. However, they exposed the biofilms to ozone by blowing ozone gas directly into the biofilm in a buffer, which is not an appropriate manner to evaluate the effects of ozone water. Nagayoshi et al. reported that ozone water showed a bactericidal effect on dental biofilm collected from human teeth ${ }^{11)}$, but we believe that different dental samples could not provide an accurate measurement because bacterial numbers were not adjusted. Altogether, there are few studies available in the literature that examine the bactericidal and cleaning effects of ozone water under appropriate experimental conditions in the field of dental science. Our study will, therefore, contribute to adding valuable insights to this discussion.

Finally, because biofilm treatment with small amounts of ozone water was not effective, we applied ozone water under flowing conditions (Fig. 3). Flowing ozone water significantly reduced bacteria in the disk compared to the control flowing water. The cleaning effect was also 
comparable to that of $\mathrm{NaOCl}$ at the same concentration (5 ppm). However, the effect was weaker than that of $\mathrm{NaOCl}$ at a higher concentration (200 ppm), which completely washed out the biofilm from the disk. $\mathrm{NaOCl}$ can be used at more than $200 \mathrm{ppm}$ in dental therapy, but it is potentially harmful to patients, and its use has limitations ${ }^{25}$. Ozone water could be an alternative disinfectant in patients that are sensitive to other disinfectants such as $\mathrm{NaOCl}$.

Taken together, our results show that the continuous application of flowing ozone water can disinfect and clean the oral cavity without severe adverse effects. However, when a dental plaque has already developed, it should first be removed by mechanical treatment such as scaling, then making ozone water effective. Additionally, ozone water might be useful for a daily dental cleaning, considering that a small ozone water generator for household use is now available. In the future, we will conduct a study regarding the daily use of ozone water in dental wash products.

\section{Acknowledgments}

We thank Rie Hada for basic examinations such as the determination of culture conditions and the collection of biofilm bacteria. We also thank Mariko Kondo for the support in experiments.

\section{Conflict of Interest}

The ozone water generator used in this study was provided by Maxell, Ltd., and their staff (K. H.) were included in the author list. However, they did not add biases to this work in any form.

\section{References}

1. Greene AK, Few BK and Serafini JC. A comparison of ozonation and chlorination for the disinfection of stainless steel surfaces. J Dairy Sci 76: 3617-3620, 1993

2. Moore G, Griffith C and Peters A. Bactericidal properties of ozone and its potential application as a terminal disinfectant. J Food Prot 63: 1100-1106, 2000

3. Elvis AM and Ekta JS. Ozone therapy: A clinical review. J Nat Sci Biol Med 2: 66-70, 2011

4. Kim JG, Yousef AE and Dave S. Application of ozone for enhancing the microbiological safety and quality of foods: a review. J Food Prot 62: 1071-1087, 1999

5. Tiwari S, Avinash A, Katiyar S, Iyer AA and Jain S. Dental applications of ozone therapy: A review of literature. Saudi Dent J 8: 105111,2017

6. Azuma K, Mori T, Kawamoto K, Kuroda K, Tsuka T, Imagawa T, Osaki T, Itoh F, Minami S and Okamoto Y. Anti-inflammatory effects of ozonated water in an experimental mouse model. Biomed Rep 2: 671-674, 2014

7. Valacchi G, Sticozzi C, Zanardi I, Belmonte G, Cervellati F, Bocci $\mathrm{V}$ and Travagli V. Ozone mediators effect on "in vitro" scratch wound closure. Free Radic Res 50: 1022-1031, 2016
8. Flemming HC, Wingender J, Szewzyk U, Steinberg P, Rice SA and Kjelleberg S. Biofilms: an emergent form of bacterial life. Nat Rev Microbiol 14:563-575, 2016

9. Hoiby N. A personal history of research on microbial biofilms and biofilm infections. Pathog Dis 70: 205-211, 2014

10. Vestby LK, Gronseth T, Simm R and Nesse LL. Bacterial biofilm and its role in the pathogenesis of disease. Antibiotics (Basel) 9: 59, 2020

11. Nagayoshi M, Fukuizumi T, Kitamura C, Yano J, Terashita M and Nishihara T. Efficacy of ozone on survival and permeability of oral microorganisms. Oral Microbiol Immunol 19: 240-246, 2004

12. Hems RS, Gulabivala K, Ng YL, Ready D and Spratt DA. An in vitro evaluation of the ability of ozone to kill a strain of Enterococcus faecalis. Int Endod J 38: 22-29, 2005

13. Huth KC, Quirling M, Lenzke S, Paschos E, Kamereck K, Brand K ,Hickel R and Ilie N. Effectiveness of ozone against periodontal pathogenic microorganisms. Eur J Oral Sci 119: 204-210, 2011

14. Hamada S and Slade HD. Biology, immunology, and cariogenicity of Streptococcus mutans. Microbiol Rev 44: 331-384, 1980

15. Koo H, Falsetta ML and Klein MI. The exopolysaccharide matrix: a virulence determinant of cariogenic biofilm. J Dent Res 92: 10651073, 2013

16. Haffajee AD and Socransky SS. Microbial etiological agents of destructive periodontal diseases. Periodontol 2000 5: 78-111, 1994

17. Hajishengallis G, Darveau RP and Curtis MA. The keystone-pathogen hypothesis. Nat Rev Microbiol 10: 717-725, 2012

18. Lamont RJ and Hajishengallis G. Polymicrobial synergy and dysbiosis in inflammatory disease. Trends Mol Med 21: 172-183, 2015

19. World Health Organization. Global priority list of antibiotic-resistant bacteria to guide research, discovery, and development of new antibiotics: 1-7, 2017

20. Smith AJ, Jackson MS and Bagg J. The ecology of Staphylococcus species in the oral cavity. J Med Microbiol 50: 940-946, 2001

21. Eduardo FP, Bezinelli LM, Gobbi MF, Santos VM, Maluf FC and Correa L. Severe oral infection caused by Pseudomonas aeruginosa effectively treated with methylene blue-mediated photodynamic inactivation. Photodiagnosis Photodyn Ther 26: 284-286, 2019

22. Nagano K, Abiko Y, Yoshida Y and Yoshimura F. Genetic and antigenic analyses of Porphyromonas gingivalis FimA fimbriae. Mol Oral Microbiol 28: 392-403, 2013

23. Hirahara Y, Iwata K and Nakamuro K. Effect of citric acid on prolonging the half-life of dissolved ozone in water. Food Saf (Tokyo) 7: 90-94, 2019

24. Tomino M, Nagano K, Hayashi T, Kuroki K and Kawai T. Antimicrobial efficacy of gutta-percha supplemented with cetylpyridinium chloride. J Oral Sci 58: 277-282, 2016

25. Mohammadi Z, Shalavi S, Moeintaghavi A and Jafarzadeh H. A review over benefits and drawbacks of combining sodium hypochlorite with other endodontic materials. Open Dent J 11 :661-669, 2017 
J.Hard Tissue Biology Vol. 30(1): 27-32, 2021 